\title{
EL VIDEOJUEGO Y LA LECTURA LITERARIA: NUEVO ESPACIO PARA LOS NATIVOS DIGITALES
}

\author{
Nieves Gutiérrez Ángel \\ Universidad de Almería
}

\begin{abstract}
RESUMEN: Nos encontramos ante una realidad social en la que la lectura no se realiza únicamente a través de libros, sino también a partir de diferentes recursos como páginas web, foros, periódicos digitales, o los videojuegos. Configurándose todos ellos como nuevos espacios para la lectura. En cuanto a estos últimos, su origen se sitúa en la década de los 80, aunque su gran auge vendría a darse en la década de los 90. Y en la actualidad, son considerados como máquinas para aprender que ofrecen al profesor una herramienta idónea de cara a que los estudiantes puedan construir y elaborar sus conocimientos mediante un instrumento para ellos empleado en su día a día y motivador. En este sentido, los videojuegos están estrechamente unidos a la lectura, y han supuesto un cambio en nuestras actitudes hacia la lectura y la escritura, y un nuevo canal de transmisión de narrativas. El presente trabajo analiza una serie de videojuegos en los que o bien se ha referencia a figuras literarias, o bien son adaptaciones directas de obras.
\end{abstract}

PALABRAS CLAVE: videojuegos, lectura literaria, referencias, adaptaciones.

\section{THE VIDEO GAME AND LITERARY READING: NEW SPACE FOR DIGITAL NATIVES}

\footnotetext{
ABSTRACT: We are facing a social reality in which reading is not produced also through books, but also to websites, forums, digital newspapers, or video games, configuring all of them as new spaces for reading. In recent years, they were published in the 1980s, although they were largely sold in the 1990s. At the same time, they offered an ideal tool for students to build and develop their knowledge. In this sense, video games are closely linked to reading, and have brought about a change in our attitudes towards reading and writing, and a new channel for transmitting narratives. The present work analyzes a series of video
} 
games in which there is a reference to literary figures, or they are direct adaptations of the works.

KEYWORDS: Video games, literary reading, references, adaptations.

Recibido: $14 / 05 / 2019$

Aceptado: 16/10/2019

Correspondencia: Nieves Gutiérrez Ángel, Universidad de Almería, Departamento de Educación, 04120 La Cañada, Almería. Email: nga212@ual.es.

\section{Concepto y ORIGEN DE los ViDeojuegos}

Una definición aproximada a qué son los videojuegos podría ser aquella que detalla a los mismos como una manera de interacción de carácter lúdico a través de sistemas de datos que pueden estar disponibles en distintos tipos de dispositivos, como ordenadores, videoconsolas, aplicaciones, plataformas, direcciones web, etc. de manera que permiten el juego a uno o incluso varios jugadores de forma simultánea, en los que se establece una interrelación entre el sujeto y el propio juego (Fonseca, 2016). Como puede comprobarse, de esta definición se desprenden una serie de características que van a estar presentes indistintamente del dispositivo en que esté disponible el videojuego en cuestión, como son el carácter lúdico e interactivo.

Para Marín (2014) el origen de los videojuegos se sitúa en la década de los 80, aunque su gran auge vendría a darse en la década de los 90. Sin embargo, para Fonseca (2016) la historia de los videojuegos se remonta hasta hace cincuenta años atrás hasta llegar a convertise en la actualidad en una de las formas de las formas de ocio más atrayentes y presentes con un gran impacto a nivel social y cultural. En este sentido, los videojuegos se corresponden con un claro reflejo de las características imperantes en nuestra sociedad (Sauquillo, Ros, y Bellver, 2008). Y han supuesto en nuestros días el origen de una nueva cultura de aprendizaje adaptada a estas nuevas características sociales, desarrollando numerosas competencias consideradas como esenciales de cara a la ciudadanía que integra el siglo XXI (Pernsky, 2001, 2006).

Por consiguiente, los videojuegos suponen una manera de experimentar distintas experiencias y poner en uso distintas habilidades (Arnold, 2014), en gran parte propiciada por una serie de factores que se relacionan tanto con la temprana edad a la que se comienza su empleo, como con la extensibilidad en las edades que se producen. Y debido también a la gran cantidad de plataformas o medios en los que están disponibles, entre los que encontramos tanto las tablets, teléfonos, portátiles, televisiones, consolas, etc., lo que les ha permitido poseer una amplia variedad de formas de configuración.

De este modo, se han llegado a postular no solo como una herramienta de aprendizaje de distintas competencias, sino también como una herramienta que promueve el aprendizaje basado en la diversión, el gozo, la creatividad, el interés y las interacciones socialesa través de la motivación tanto intrínseca como extrínseca del alumnado (Alamri, 2016). 


\section{Videojuegos, SOCIEDAD Y edUCACIÓN: APRENDIZAJE GLOBAL Y SIGNIFICATIVO}

Dentro del contexto educativo, la presencia y utilización de las TIC se corresponde en la actualidad con un hecho de carácter esencial, y ha supuesto tanto un cambio a nivel social como a nivel educativo. Tanto es así, que incluso su calado ha llegado a manifestarse a nivel legislativo a través de la Ley Orgánica de Mejora de la Calidad Educativa (2013) (LOMCE), al mencionar las denominadas "habilidades digitales".

Para Martínez (2013) existen dos grandes focos de origen del empleo de los videojuegos en el aula. Así, mientras que el primero de ellos se corresponde con el empleo de videojuegos comercializados, el segundo tipo, se corresponde con el empleo de videojuegos diseñados ad hoc para un proceso de aprendizaje, el cual cuenta con indicaciones tanto de carácter didáctico, como curriculares. A esta distinción, Astete (2015) añade una nueva modalidad, que en definitiva, supone una mezcla de las dos anteriores, es decir, a partir de un videojuego comercial, se elabora un proyecto de enseñanza y aprendizaje.

Por lo tanto, desde el contexto educativo los videojuegos son considerados como máquinas para aprender (Gee, 2003), y sus beneficios se corresponden con (Ashikur, 2016; Murias, Kwok, Castillejo, Liu, y laria, 2016; Santos, Cernada, y Lorenzo, 2014; Salimi, 2016):

- Una gran contribución al proceso de enseñanza y aprendizaje a partir del fomento del pensamiento reflexivo y el razonamiento

- El fomento de procesos psicológicos básicos como la memoria o la atención

- La propuesta de distintas estrategias para la resolución de conflictos y el trabajo colaborativo y cooperativo

- La promoción de la superación como metáfora para generar un mayor aprendizaje

- Desarrollo de las relaciones interpersonales y conductas prosociales

- Potencia el aprendizaje de la denominada "alfabetización digital"

- Mejoran la capacidad espacial

En definitiva, la utilización de los videojuegos repercute positivamente en habilidades como la percepción, la atención o la flexibilidad cognitiva (Green y Bavelier, 2015). Así como en los aprendizajes curriculares, o en la potenciación de los distintos tipos de inteligencias (Del Moral, Fernández, y Guzmán, 2015). Y la inclusión de los videojuegos como recurso educativo despierta en el alumnado el interés por el aprender, potenciando el desarrollo de las conductas sociales y las relaciones interpersonales, y ofreciendo la posibilidad de trabajar distintos contenidos curriculares de manera transversal (Marín, 2012). Además, fomentan aspectos como la autoestima, la autoimagen, la creatividad y la fantasía, el trabajo cooperativo, o la búsqueda y utilización de distintos tipos de información (Marín, López y Maldonado, 2015). Promueven un tipo de aprendizaje que se caracteriza por ser más práctico que 
teórico a traves de la promocion de novedosos estilos de aprendizaje interactivos y autónomos (Charles y McAlister, 2004) y se corresponden con un recurso motivador, excitante y gratificante, que va aumentando su complejidad a lo largo de distintos niveles, a medida que también lo hacen las habilidades de la persona que juega (Green y Bavelier, 2015).

Sin embargo, no hemos de olvidar la influencia que en este caso la cultura urbana, ha tenido en los videojuegos y en los lazos establecidos en este caso con la lectura. Para conocer mejor los textos de la cultura urbana y sus conexiones véase el trabajo de Quiles y Martos (2019).

De la misma manera, los videojuegos aportan una serie de elementos innovadores que no han estado presentes antes en el contexto educativo en ninguna de las herramientas empleadas en los procesos de enseñanza y aprendizaje. $Y$ ofrecen al profesor una herramienta idónea de cara a que los estudiantes puedan construir y elaborar sus conocimientos mediante un instrumento que para el alumnado es motivador y está muy presente en su día a día. Suponen un recurso educativo innovador, eficaz y significativo en los procesos de enseñanza y aprendizaje (Sampedro y McMullin, 2015).

Para Morales y Mora (2015) los tipos de aprendizaje que desde la utilización de los videojuegos como herramienta didáctica se potencian son los siguientes:

- El aprendizaje formal

- El aprendizaje informal, entendido como aquel que se desarrolla en todos los entornos próximos al alumno, sin contar al entorno escolar. Es decir, todos aquellos contextos en los que el alumno extrapola sus conocimientos

- El aprendizaje de carácter implícito, el cual se desarrolla sin que el alumno se de cuenta

- El aprendizaje vicario, en este caso a través de la observación y comprensión de las conductas observadas

- El aprendizaje cooperativo, a través de las interrelaciones personales establecidas con el grupo de iguales

- El aprendizaje a distancia, el cual no se da únicamente en el aula, sino que puede darse en multitud de lugares y además de forma simultánea

Por todos estos motivos, consideramos que los videojuegos deben de comenzar a ser contemplados por el profesorado como una estrategia o recurso educativo, aprovechando tanto su carácter lúdico, como la gran expansión que han tenido. Sin embargo, esto no significa cambiar por completo los medios empleados en tal proceso, sino más bien, la incorporación de los mismos como un recurso educativo más (Alamri, 2016). Además, también hemos de educar en el uso responsable de estos dispositivos, para evitar adiciones o problemas que de su empleo abusivo u obsesivo pudieran derivarse.

En este sentido, las investigaciones más novedosas en el terreno educativo están focalizadas en cómo estos pueden determinar e influir en los aprendizajes alcan- 
zados por el alumnado (Herrero, Moral, y Torralba-Burrial, 2017). Destacan el denominado "Aprendizaje Basado en Juegos Digitales (ABJD)" que tiene por finalidad máxima el fomentar el aprendizaje mediante la utilización de videojuegos a través de actividades con un gran carácter lúdico mediante las cuales se propone dar respuesta a distintas situaciones cuya solución dota al alumnado de distintas emociones relacionadas con el logro (Herrero et al., 2017). Son numerosos los trabajos que han demostrado su efectividad (Qian y Clark, 2016). No obstante, hemos ser precavidos, ya que la utilización de los videojuegos en el terreno educativo puede Ilegar a tener consecuencias totalmente contrarias a las deseadas, convirtiéndose en una herramienta lúdica y no educadora (Schouten, Tieben, Van de Ven, y Schouten, 2011).

A modo de conclusión, la incorporación de los videojuegos como herramientas de aprendizaje en el contexto educativo da como resultado la creación de nuevas experiencias de innovación didáctica, que facilitan la promoción y adquisición de distintos tipos de habilidades, competencias y capacidades cognitivas, así como el fomento de la motivación del alumnado. Para consultar investigaciones más actuales, se pueden consultar distintos trabajos recientes como los elaborados por Del Cerro y Morales (2017) y Toledo y Sánchez-García (2017).

\section{LOS VIDEOJUEGOS: UN NUEVO ESPACIO PARA LA LECTURA}

En primer lugar, conviene aclarar qué entendemos por leer. Para ello, hemos de ser conscientes de que no podemos abordar dicho concepto desde un punto de vista únicamente inherente al ser humano, sino que tenemos que ser conscientes de la gran influencia que en él supone el componente sociocultural de la lectura (Chartier, 2013). O, dicho en otras palabras, siguiendo a Solé (1992), la lectura es el proceso de "decir, narrar o contar" lo escrito, que da un paso más allá considerando que a partir de esa lectura se produce la comprensión. Es decir, que desde esta afirmación se desprenden dos ideas principales: la decodificación de los códigos, y la comprensión de la literalidad y estructura del mensaje. Al respecto, compartimos la hipótesis de Serna-Rodrigo y Rovira-Collado (2016) quienes apuestan por una visión de los videojuegos unidos y relacionados con la lectura, en la que en numerosas ocasiones sin el hecho de leer no se puede continuar jugando al mismo.

Conceptos que aparecen unidos al de intertexto, considerado en este caso como una herramienta clave para que la lectura sea eficaz y comprensiva. Es decir, el conglomerado de conocimientos que el lector fragua sobre el mensaje que le ofrece el propio texto, a partir del cual inspecciona, analiza, da por válido o no, y constituye los nuevos conocimientos que le propician el contenido que lee (Molina, 2017). Y junto con ello, hemos de tener en cuenta la consideración del propio lector como un sujeto activo y protagonista en dicho proceso, el cual elabora y construye el significado del texto literario, dejando atrás antiguas concepciones del texto cerrado y pasivo (Molina, 2017).

Estas ideas nos conducen también a hablar de comprensión y competencia lectora. Al respecto, tanto un concepto como el otro, engloban distintos tipos de compe- 
tencias (cognitivas, y metacognitivas) así como la comprensión, la utilización, la implicación y la participación en la lectura. Sin embargo, mientras que la comprensión lectora es la capacidad de comprender objetivamente el mensaje que un autor transmite por medio de un texto (Zorrila, 2005), la competencia lectora es la capacidad de un sujeto para utilizar su propia competencia lectora en la sociedad (Pérez, 2014). En relación con estas ideas, Pérez (2014) establece siete niveles de competencias, que se corresponden con los siguientes: literal, representativo, inferencial, crítico, emocional, creador y metacognitivo.

Sin embargo, si damos un paso más allá y nos referimos a la lectura plena de un texto con intención estética estaremos hablando de competencia literaria "entendida como el conjunto de saberes y destrezas de carácter literario que permite definir, desde el punto de vista pragmático y didáctico, la capacidad de los individuos para participar de manera activa y eficaz en situaciones de comunicación (orales o escritas) de mensajes literarios o de intención estética" (Molina, 2017: 114). O incluso de competencia lectoliteraria comprendida como "el conjunto de saberes específicos, teóricos y prácticos que nos permiten interpretar de manera pragmática y eficaz mensajes escritos de intención escrita" (Molina, 2017: 114).

Es decir, un conjunto de conocimientos y modalidades ineludibles para comprender las obras literarias y disfrutar con ellas tras su análisis, que se traducen en distintas destrezas relacionadas con la formación del hábito lector autorregulado, la capacidad de disfrute de la lectura, y el acercamiento e inclusión con el mundo que ofrece la obra literaria (Colomer, 1998)

Cabe cuestionarnos entonces, ¿son los videojuegos un producto narrativo? Son muchos los autores que consideran que en la actualidad los videojuegos se han convertido en un novedoso y legítimo cuentacuentos en la sociedad (Balbuena, 2015), o dicho con otras palabras, hablan del acercamiento entre el juego y la narrativa, lo cual supone un cambio en nuestras actitudes hacia la lectura y la escritura, y un nuevo canal de transmisión de narrativas (Ayala, 2010). Características que además permiten al jugador ir más allá en la historia, escogiendo un desarrollo más complejo y duradero en el tiempo, creando la denominada ilusión de libertad narrativa (Medina, 2015).

Por ello, desde estas líneas apostamos por un concepto de narratividad en la que emergen la literatura, el cine, el cómic, o los videojuegos, a partir de la narrativa artística (Ureña, 2015). Podemos decir que "En vez de que le narren, es el propio jugador el que tiene que llevar a cabo acciones para hacer avanzar la historia (...). Si el jugador no hace nada, la acción se para. Desde este punto de vista, el desplazamiento por el mundo del juego es una de las principales acciones narrativas" (Manovich 2005: 315). Al hilo de estas ideas, los videojuegos son considerados como grandes muestras de la literatura en general, y del cibertexto, en particular (Espen Aarseth, 1997).

En relación con ello existen múltiples clasificaciones en torno a los tipos de videojuegos, entre las que adquiere especial relevancia la realzada por Pérez Latorre (2011). Dicho autor distingue cuatro categorías por excelencia a partir de 
distintos criterios, entre ellos, la finalidad del jugador. Con respecto a la misma, a su vez establece que la finalidad de una persona que juega puede ser triple: Competitiva (su rol es ganar o perder la partida). Comprensiva (sobre el funcionamiento de un determinado sistema). O de descubrimiento y construcción de una experiencia narrativa (dentro de la que se incluirían en mayor medida tanto los videojuegos de aventura, como los de rol, aunque también los de acción o simulación).

En definitiva, en la sociedad actual la lectura no se realiza únicamente a través de libros, sino también a partir de diferentes recursos como páginas web, foros, periódicos digitales, o los videojuegos. Configurándose todo ellos como nuevos espacios para la lectura y dando lugar a un nuevo tipo de lector: el lector digital (Martos y Rösing, 2009; Martos y Campos, 2013).

Por todo ello, es preciso en este momento aclarar qué entendemos por hipertexto, un concepto que ha existido siempre, con la publicación de Genette de Palimpsestos. Sin embargo, el hipertexto goza en la actualidad de una gran relevancia, debido a las nuevas formas hipertextuales y de lectura multimodal, quedando definido como un conjunto de distintos textos cuya disponibilidad está en formato digital y puede conducir de un texto a otro. Los cuales permiten al lector escoger aquello que se desea leer, siendo una opción de lectura de carácter abierto (Lluch y Barrena, 2007).

A partir de todas estas ideas, proponemos el análisis de 14 videojuegos partiendo de la clasificación acerca de los mismos realizada por Serna-Rodrigo y RoviraCollado (2016: 11) a partir de las aportaciones de carácter narrativo o literal que ofrecen:

- Aventuras gráficas: Videojuegos interactivos basados en investigación, conversaciones y empleo de objetos a través de una interfaz.

- Narrativa digital: Historias diseñadas para jugadores a través del soporte videojuego y que se desarrollan gracias a las funcionalidades del hardware en cuestión.

- Diseño de mundos posibles: Videojuegos que facilitan herramientas a sus jugadores para diseñar sus propios espacios, personajes y aventuras.

- Presencia de referencias literarias: Videojuegos que incluyen elementos concretos de obras literarias ya existentes: personajes, mundos, aventuras...

- Adaptaciones directas: Videojuegos que reproducen, con relativa fidelidad, obras literarias ya publicadas: novelas, cómics, películas... También incluimos aquellos títulos que han dado pie a una posterior obra literaria.

En este trabajo, nos vamos a centrar en las últimas clasificaciones, es decir, en aquellos videojuegos que poseen referencias literarias, y en los videojuegos que son adaptaciones directas de obras literarias. 


\section{VIDEOJUEGOS CON TEMÁTICA LITERARIA: UNA APROXIMACIÓN}

\subsection{Videojuegos con presencia de referencias literarias}

\begin{tabular}{|c|c|c|c|c|}
\hline Nombre & Hipotexto & Tipo de juego & Descripción & Personajes \\
\hline Dante's Inferno & $\begin{array}{l}\text { La Divina } \\
\text { Comedia, de } \\
\text { Dante Alighieri }\end{array}$ & $\begin{array}{l}\text { Acción } \\
\text { aventura }\end{array}$ & $\begin{array}{l}\text { A partir de la am- } \\
\text { bientación de la } \\
\text { obra original en } \\
\text { este videojuego el } \\
\text { jugador se corres- } \\
\text { ponde con Dante } \\
\text { y puede crear una } \\
\text { historia paralela }\end{array}$ & $\begin{array}{l}\text { Comparte con la obra la historia de Dante, rei- } \\
\text { maginado como un caballero templario y Virgi- } \\
\text { lio por los nueve círculos del infierno (el limbo, } \\
\text { la lujuria, la gula, la codicia, la ira, la mentira, } \\
\text { la avaricia, la herejía y la traición) hasta el en- } \\
\text { cuentro con el diablo para salvar a Beatriz de } \\
\text { sus garras. Además, también hay presentes en el } \\
\text { mismo otros monstruos de la obra. Sin olvidar } \\
\text { la presencia de personajes como Platón y Aris- } \\
\text { tóteles y un monstruoso rey Minos que hace las } \\
\text { veces de juez del infierno }\end{array}$ \\
\hline $\begin{array}{l}\text { Alice: Madness } \\
\text { Returns y } \\
\text { American } \\
\text { McGee's Alice }\end{array}$ & $\begin{array}{l}\text { Se basa en dos } \\
\text { obras litera- } \\
\text { rias de Lewis } \\
\text { Caroll, Alicia } \\
\text { en el País de } \\
\text { las Maravillas } \\
\text { y A través del } \\
\text { espejo }\end{array}$ & $\begin{array}{l}\text { Acción y } \\
\text { plataformas }\end{array}$ & $\begin{array}{l}\text { Aunque toma re- } \\
\text { ferencias de estas } \\
\text { obras, el videojue- } \\
\text { go posee un carác- } \\
\text { ter más promotor } \\
\text { de la violencia y la } \\
\text { crueldad. En este } \\
\text { caso, el jugador se } \\
\text { convierte en Alicia }\end{array}$ & $\begin{array}{l}\text { Alicia, el gato de Chesire, el conejo blanco o } \\
\text { la reina de corazones son los protagonistas del } \\
\text { videojuego. Sin embargo, el carácter del mis- } \\
\text { mo es mucho más oscuro, demente y violento } \\
\text { que la obra original. La protagonista se presenta } \\
\text { como una persona desequilibrada psicológica- } \\
\text { mente a partir de un duelo, que consigue es- } \\
\text { capar del manicomio y vive en Londres, donde } \\
\text { lucha contra la reina de corazones y el tren in- } \\
\text { fernal. Por lo que no tiene demasiada relación } \\
\text { argumental con el texto original }\end{array}$ \\
\hline $\begin{array}{l}\text { La saga Assassins } \\
\text { creed }\end{array}$ & $\begin{array}{l}\text { Personajes his- } \\
\text { tóricos }\end{array}$ & $\begin{array}{l}\text { Acción } \\
\text { aventura }\end{array}$ & \multicolumn{2}{|c|}{$\begin{array}{l}\text { El jugador es Desmond Miles, quien pertenece a la saga de los ase- } \\
\text { sinos cuyos mayores enemigos son los templarios. El jugador pue- } \\
\text { de en todo momento actuar con toda libertad en el mundo virtual } \\
\text { creado. } \\
\text { Una de las grandes aportaciones de este juego reside en ser una es- } \\
\text { pecie de máquina del tiempo que es capaz de trasladarnos a otras } \\
\text { épocas y lugares (prestando especial atención a la fiel reproducción } \\
\text { de los edificios históricos). Atendiendo a cada época y personajes, } \\
\text { cabe destacar las siguientes: } \\
\text { - Juego AC. Época: Tercera cruzada (1191). Aparecen personajes } \\
\text { históricos como Ricardo Corazón de León. Y ciudades como Jeru- } \\
\text { salén o Damasco. } \\
\text { - Juegos ACIl y AC BRO. Época: Renacimiento (1499). Aparecen } \\
\text { personajes históricos como Leonardo Davinci, Maquiavelo, o el } \\
\text { Papa Alejandro VI. Y ciudades como Venecia, Florencia, Navarra } \\
\text { o Roma. } \\
\text { - Juego AC REV. Época: Renacimiento (1511). Aparecen personajes } \\
\text { históricos como Piris Reis o el príncipe Ahmet. Y ciudades como } \\
\text { Estambul. }\end{array}$} \\
\hline
\end{tabular}




\begin{tabular}{|c|c|c|c|c|}
\hline Nombre & Hipotexto & Tipo de juego & Descripción & Personajes \\
\hline $\begin{array}{l}\text { La saga Assassins } \\
\text { creed }\end{array}$ & $\begin{array}{l}\text { Personajes his- } \\
\text { tóricos }\end{array}$ & $\begin{array}{l}\text { Acción } \\
\text { aventura }\end{array}$ & \multicolumn{2}{|c|}{$\begin{array}{l}\text { - Juego AC III. Época: Revolución americana (1753-1783). Apare- } \\
\text { cen personajes históricos como Charles Lee, Ceorge Washington } \\
\text { o Thomas Jefferson. Y ciudades como Boston, Nueva York, o Fila- } \\
\text { delfia. } \\
\text { - Juego AC BLO. Época: Cruzadas (1192). Aparecen personajes his- } \\
\text { tóricos como Armand Bouchart. Y ciudades como Chipre. } \\
\text { - Juego AC DIS. Época: Renacimiento (1490). Aparecen personajes } \\
\text { históricos como Cristóbal Colón o Isabel la católica. Y ciudades } \\
\text { como Zaragoza, Barcelona o Granada. } \\
\text { - Juego AC IV. Época (Siglo XVIII- 1717). Aparecen personajes his- } \\
\text { tóricos como Barbanegra. Y ciudades como La Habana. }\end{array}$} \\
\hline $\begin{array}{l}\text { The Witcher, la } \\
\text { saga }\end{array}$ & $\begin{array}{l}\text { Basada en La } \\
\text { Saga de Ceralt } \\
\text { de Rivia o tam- } \\
\text { bién conocida } \\
\text { como La Saga } \\
\text { del brujo, son } \\
\text { un total de } \\
\text { ocho libros de } \\
\text { aventuras en las } \\
\text { que el protago- } \\
\text { nista es uno de } \\
\text { los últimos bru- } \\
\text { jos de la tierra }\end{array}$ & Juego de rol & $\begin{array}{l}\text { Se trata de una saga } \\
\text { de videojuegos que } \\
\text { cuentan las aventu- } \\
\text { ras de Geralt, por } \\
\text { medio de distintas } \\
\text { misiones que el ju- } \\
\text { gador debe ir com- } \\
\text { pletando }\end{array}$ & $\begin{array}{l}\text { En cuanto a los videojuegos existen un total de } \\
\text { cinco, que se corresponden con The Witcher, } \\
\text { The Witcher 2: Assassins of Kings, The Witcher } \\
\text { 3: Wild Hunt, Gwent: The Witcher Card Came } \\
\text { y hronebreaker: The Witcher Tales. En cuanto al } \\
\text { papel del jugador existen tres estilos de com- } \\
\text { bate que se desarrolla en un mundo fantástico } \\
\text { y medieval }\end{array}$ \\
\hline $\begin{array}{l}\text { Las aventuras de } \\
\text { Sherlock Holmes } \\
\text { (saga) }\end{array}$ & $\begin{array}{l}\text { El videojuego } \\
\text { original está } \\
\text { basado en la } \\
\text { obra Las aven- } \\
\text { turas de Sher- } \\
\text { lock Holmes. }\end{array}$ & $\begin{array}{l}\text { Acción } \\
\text { aventura }\end{array}$ & $\begin{array}{l}\text { Cada uno de los } \\
\text { juegos que com- } \\
\text { ponen a esta saga, } \\
\text { tiene un hilo argu- } \\
\text { mental y una trama } \\
\text { que no se corres- } \\
\text { ponde con la obra } \\
\text { literaria. Los pro- } \\
\text { tagonistas son el } \\
\text { detective Sherlock } \\
\text { Holmes y su com- } \\
\text { pañero Watson. }\end{array}$ & $\begin{array}{l}\text { El jugador puede escoger tanto a uno como al } \\
\text { otro, y además puede jugar en primera o en ter- } \\
\text { cera persona a través de la resolución de puzles, } \\
\text { búsqueda de pistas, y resolver misterios. Dentro } \\
\text { de esta saga podemos encontrar los siguientes } \\
\text { videojuegos: Sherlock Holmes: El Misterio de } \\
\text { la Momia. Sherlock Holmes: el Pendiente de } \\
\text { Plata. Sherlock Holmes: La Aventura. Sherlock } \\
\text { Holmes y el rey de los ladrones. Sherlock Hol- } \\
\text { mes: El Misterio de la Alfombra Persa. Sherlock } \\
\text { Holmes contra Jack el Destripador. Sherlock } \\
\text { Holmes y el Misterio de la Casa Osborne. El } \\
\text { Testamento de Sherlock Holmes. Sherlock Hol- } \\
\text { mes: Crímenes y Castigos. Sherlock Holmes: } \\
\text { The Devil's Daughter. }\end{array}$ \\
\hline $\begin{array}{l}\text { Dracula: } \\
\text { Resurrection }\end{array}$ & $\begin{array}{l}\text { Es una adapta- } \\
\text { ción no oficial } \\
\text { de la novela de } \\
\text { Drácula }\end{array}$ & $\begin{array}{l}\text { Acción } \\
\text { aventura }\end{array}$ & $\begin{array}{l}\text { Se puede afirmar } \\
\text { que toma aspectos } \\
\text { de la misma y su- } \\
\text { pone una continua- } \\
\text { ción de la historia }\end{array}$ & $\begin{array}{l}\text { Toma de la obra literaria al protagonista, al cual } \\
\text { el jugador encara en primera persona. A partir } \\
\text { de ahí, la historia torna hacia un argumento to- } \\
\text { talmente distinto al de la obra original de la que } \\
\text { adopta al personaje }\end{array}$ \\
\hline
\end{tabular}




\begin{tabular}{|c|c|c|c|c|}
\hline Nombre & Hipotexto & Tipo de juego & Descripción & Personajes \\
\hline Maldita Castilla & $\begin{array}{l}\text { Es un videojuego } \\
\text { de origen espa- } \\
\text { ñol inspirado en } \\
\text { la mitología me- } \\
\text { dieval castella- } \\
\text { na, la literatura } \\
\text { medieval espa- } \\
\text { ñola y las nove- } \\
\text { las de caballería }\end{array}$ & $\begin{array}{l}\text { Acción } \\
\text { aventura }\end{array}$ & \multicolumn{2}{|c|}{$\begin{array}{l}\text { El jugador es un caballero llamado don Ramiro a quien junto con } \\
\text { don Diego, Mendoza y Quesada, el rey Alfonso VI de León encarga } \\
\text { una misión para salvar a una moura. Otros seres mitológicos al igual } \\
\text { que este último, presentes en el videojuego se corresponden con la } \\
\text { presencia de basiliscos o gamusinos. Incluso en el videojuego se hace } \\
\text { alusión a "Quijote" personaje principal de la obra Don Quijote de } \\
\text { la Mancha }\end{array}$} \\
\hline Nier Automata & $\begin{array}{l}\text { Pese a que pue- } \\
\text { da parecer un } \\
\text { videojuego muy } \\
\text { ficticio ampara- } \\
\text { do en el recu- } \\
\text { rrente tema de } \\
\text { humanos frente } \\
\text { a máquinas, la } \\
\text { presencia de } \\
\text { personajes lite- } \\
\text { rarios se hace } \\
\text { presente nada } \\
\text { más comenzar } \\
\text { en juego }\end{array}$ & Acción y rol & $\begin{array}{l}\text { Escena inicial de } \\
\text { Adán y Eva, perso- } \\
\text { najes de la Biblia, } \\
\text { en la que incluso } \\
\text { aparece la manza- } \\
\text { na, fruto prohibido }\end{array}$ & $\begin{array}{l}\text { Este videojuego versa acerca de un conflicto } \\
\text { ficticio entre humanos y máquinas. A partir del } \\
\text { mismo los humanos tienen que huir a la luna }\end{array}$ \\
\hline $\begin{array}{l}\text { The Binding of } \\
\text { Isaac }\end{array}$ & $\begin{array}{l}\text { En ester caso } \\
\text { está inspirado } \\
\text { en la historia } \\
\text { del Sacrificio } \\
\text { de Isaac recogi- } \\
\text { do en la Biblia } \\
\end{array}$ & Acción & $\begin{array}{l}\text { Como personajes } \\
\text { podemos encontrar } \\
\text { al propio Isaac, su } \\
\text { madre o incluso } \\
\text { Dios, Caín, Judas o } \\
\text { Samson }\end{array}$ & $\begin{array}{l}\text { El jugador es Isaac, un niño que debe derrotar } \\
\text { a su madre }\end{array}$ \\
\hline
\end{tabular}

\subsection{Obras literarias versionadas en videojuego}

\subsubsection{World Warz}

Se trata de un juego multijugador para hasta cuatro integrantes en la que se juega en tercera persona. Este videojuego es una adaptación de la novela con la que comparte nombre, en la que el protagonista tiene que sobrevivir a un ataque zombi. Este juego es además categorizado dentro del grupo de acción y aventura.

\subsubsection{Metro 2033}

Comparte nombre con el best seller que da origen al mismo. Además, ambos pertenecen al mismo autor. Está ambientada a partir del mapa de metro de Rusia en la que el protagonista es Artyom. 


\subsubsection{Call of Cthulhu}

Este videojuego está basado en el relato corto La llamada de Cthulhu y el juego de rol que posee el mismo nombre. La temática del mismo gira en torno a su protagonista, Edward Pierce, un veterano reconvertido a detective privado que tiene que resolver un caso muy particular tras haber sufrido una situación personal adversa. A lo largo de videojuego se pueden comprobar elementos propios de la obra literaria, como el entorno en que se desarrolla, personajes, lenguaje, y las características propias de la psique del protagonista.

\subsubsection{La saga Harry Potter}

Se trata de una serie de videojuegos de lógica que siguen la trama de cada una de las novelas y han sido publicados en fechas similares a las mismas. En ellas, el jugador encara al protagonista y se sitúan en la escuela de magia Hogwarts. Una temática recurrente en cada uno de los juegos son los hechizos. Dentro de esta serie de videojuegos se encuentran: Harry Potter y la piedra folosofal, Harry Potter y la cámara secreta, Harry Potter: Quidditch Copa del mundo, Harry Potter y el prisiones de Azkaban, Harry Potter y el caliz de fuego, Harry Potter y la orden del fénix, Harry Potter y el misterio del príncipe, Lego Harry Potter, Harry Potter y las reliquias de la muerte (parte uno y parte dos), y Harry Potter for Kinect.

\subsubsection{Eragon}

Es un videojuego de acción y aventuras que sigue el hilo argumental del libro homónimo. En él, el jugador en tercera persona es Eragon, el encargado de llevar a cabo distintos combates. Además, a través del desarrollo de la historia permite jugar en solitario o dos jugadores.

\section{Conclusiones}

Los enormes cambios, avances y novedades que las tecnologías suponen en la sociedad actual están dando lugar a que la lectura lineal, y junto con ella los textos físicos, pierdan importancia, relevancia e interés para los jóvenes de nuestra sociedad.

Al respecto, no todo es negativo, pues han surgido a partir de estas novedades distintos ámbitos nuevos de lectura. En este sentido, se han abierto nuevas puertas hacia leer y narrar historias, dentro de las que se encuentran los videojuegos, que se han consolidado como grandes propulsores de la lectura.

Como conclusión, dentro de este apartado, apostamos por la idea de que este tipo de videojuegos tienen una doble ventaja: por un lado, pueden ser una herramienta para la mejora de la competencia lectoliteraria. Mientras que, por otro lado, pueden llegar a ser un elemento motivador que incite a la lectura de obras clásicas (SernaRodrigo y Rovira-Collado, 2016). 
Como aspectos positivos hemos de destacar:

- Son numerosos los juegos que son muy adecuados de cara a la estimulación cognitiva de alumnos que tengan alguna dificultad de aprendizaje, fundamentalmente a nivel visual y psicomotor.

- Aspectos relacionados con el sexismo cada vez son más combatidos en los videojuegos y, por lo tanto, pueden ser una herramienta para trabajar la coeducación.

- También son numerosos los videojuegos que permiten la interaccion y participación a nivel familiar.

- Destacan los videojuegos que ofrecen contenidos culturales, como por ejemplo los de contenido histórico, suponiendo uno gran herramienta para la enseñanza de estas temáticas.

- Además, son muchos los videojuegos que poseen un gran carácter positivista.

En el sentido contrario, como aspectos negativos destacan los siguientes:

- Existen videojuegos que promueven la violencia a través de su alto contenido violento, fomentando actitudes y comportamientos agresivos por medio de su exposición.

- También hemos de destacar la presencia de estereotipos sexistas en numerosos videojuegos que ofrecen una imagen de la mujer inferior a la del hombre.

- La existencia de videojuegos violentos se convierte en interesante únicamente para los jóvenes, lo que aumenta el desfase generacional en cuanto al empleo de los mismos.

- Los personajes pueden aparecer en ocasiones como faltos de personalidad o estereotipados en una imagen predeterminada de la sociedad.

- Son numerosos los videojuegos que desde el inicio de su creación hasta nuestros días han destacado por su carácter negativo.

\section{REFERENCIAS BIBLIOGRÁFICAS}

Alamri, A. (2016). Should Video Games Be Included in the Learning Process? International Journal of Education, 8(1), 23-33. http://doi.org/10.5296/ije.v8i1.8388.

Arnold, B. J. (2014). Gamification in education. ASBBS Proceedings, 21(1), 32.

Astete, M. G. (2015). Videojuegos para apoyar el desarrollo de competencias TIC en la formación docente. Revista de Educación a Distancia, 44, 1-18.

Ayala, N. A. C. (2010). Videojuegos: máquinas del tiempo y mutaciones de la subjetividad. Signo y Pensamiento, 29(57), 162-177.

Balbuena, A. C. (2015). El videojuego como nuevo producto narrativo: la hipertextualidad en World of Warcraft. Tonos digital: Revista Electrónica de Estudios Filológicos, 28, 1-15. 
Cerro, F. y Morales, G. (2017). Realidad Aumentada como herramienta de mejora de la inteligencia espacial en estudiantes de educación secundaria. Revista de Educación a Distancia, 54, 1-14. http://doi.org/10.6018/red/54/5.

Charles, D. y McAlister, M. (2004). Integrating Ideas about Invisible Playgrounds from Play Theory into Online Educational Digital Games. M. Rauterberg (Ed.), Entertainment Computing -ICEC 2004 (pp. 598-601). Berlin, Heidelberg: Springer. Lecture Notes in Computer Science 3166.

Chartier, R. (2013). Leer la lectura. Trama \& Texturas, 21, 11-23.

Colomer, T. (1998). La formación del lector literario: narrativa infantil y juvenil actual. Salamanca: Fundación Germán Sánchez Ruipérez.

Contreras, R. S. (2013). Acercamiento a las características de los videojuegos y sus beneficios en el aprendizaje.

Drummond, A. y Sauer, J. D. (2014). Video-games do not negatively impact adolescent academic performance in science, mathematics or reading. PloS one, 9(4), 87-94.

Fonseca, N. (2016). Hitting the "play" button: the aesthetic values of videogame experience. Itinera, 11, 75-96.

Gee, J. P. (2003). What Video Games Have to Teach Us About Learning and Literacy. New York: Palgrave Macmillan.

Green, C. S. y Bavelier, D. (2015). Action video game training for cognitive enhancement. Current Opinion in Behavioral Sciences, 4, 103-108. http://doi. org/10.1016/j.cobeha.2015.04.012.

Herrero, M., Moral, M. E. D. y Torralba-Burrial, A. (2017). Aprendizajes científicos y educación ambiental en entornos lúdicos: potencialidad de un videojuego en línea sobre desastres naturales para la educación formal de maestros. En Actas del $\checkmark$ Congreso Internacional de Videojuegos y Educación, Puerto de la Cruz, Tenerife. http://riull.ull.es/xmlui/handle/915/6680.

Holland, W., Jenkins, H. y Squire, K. (2002). Video game theory. En Wolf, M. y Perron, B. (Eds), The video game theory reader (pp. 25-46). Nueva York, Londres: Routledge.

Ley Orgánica 8/2013, de 9 de diciembre, para la mejora de la calidad educativa. Boletín Oficial del Estado. Madrid, 10 de diciembre de 2013, núm. 295, pp. 97858-97921.

Lluch, G. y García, P. B. (2006). Lectura y literatura infantil y juvenil en la sociedad globalizada. En Entre líneas anda el juego: La literatura infantil y juvenil como vía para la construcción del lector (pp. 93-114). Salamanca: Fundación Germán Sánchez Ruipérez.

Lomas, D., Patel, K., Forlizzi, J. L. y Koedinger, K. R. (2013). Optimizing challenge in an educational game using large-scale design experiments. En Proceedings of the SIG$\mathrm{CHI}$ Conference on Human Factors in Computing Systems, Paris, Francia (pp 89-98), 
Manovich, L. (2005). El lenguaje de los nuevos medios de comunicación. La imagen en la era digital. Barcelona: Paidós.

Marín, V. (2012). El ayer y hoy de los videojuegos y juegos digitales. En Marín, V. (Coord.), Los videojuegos y juegos digitales como materiales educativos (pp. 1733). Madrid: Síntesis.

Marín, V. (2014). Aprendiendo a través de los videojuegos: la opinión de los y las jóvenes educadores y educadoras. Revista de Estudios de Juventud, 106, 149-165.

Marín, V., López, M. y Maldonado, G. (2015). Can Gamification Be Introduced within Primary Classes? Digital Education Review, 27, 55-68.

Martínez, H. (2013). Los videojuegos, más que un enemigo, pueden ser un aliado de la educación. Chile: El Mercurio.

Martos, E. y Rösing, T. (2009). Prácticas de lectura y escritura. Brasil: UPF-Universidades Lectoras.

Martos, E. y Campos, M. M. (Eds.). (2013). Diccionario digital de nuevas formas de lectura y escritura:(DiNle). Red Internacional de Universidades Lectoras.

Medina, P. (2015). Los raíles ocultos, narrativa multiopción invisible de videojuegos. Espéculo: Revista de Estudios Literarios, 54, 66-79.

Molina, M. (2017). Desarrollo y evaluación de la competencia lecto-literaria en el Bachillerato.

Morales, C. D. R. M. y Moya, J. J. M. (2015). Adentrándonos en el laberinto, ¿qué le ocurrirá si juega? Ludicamente, 4(7), 1-18.

Murias, K., Kwok, K., Castillejo, A. G., Liu, I. y laria, G. (2016). The effects of video game use on performance in a virtual navigation task. Computers in Human Behavior, 58, 398-406. http://doi.org/10.1016/j.chb.2016.01.020.

Pérez, E. J. (2014). Comprensión lectora vs Competencia lectora: qué son y qué relación existe entre ellas. Investigaciones sobre Lectura, 1, 65-74.

Prensky, M. (2006). Don't bother me, Mom, I'm learning! How computer and video games are preparing your kids for 21 st century success and how you can help! St. Paul, MN: Paragon House.

Quiles, M. C. y Martos, E. (2019). Los textos de la calle: cultura urbana y acciones de emprendimiento para la formación de lectores. Pedagogía social, Revista interuniversitaria, 33, 31-42.

Qian, M. y Clark, K. M. (2016). Game based learning and 21st century skills: a review of recent research. Computer Human Behavior, 63, 50-58. http://doi.org/10.1016/j. chb.2016.05.023.

Sampredro, B. E. y McMullin, K. J. (2015). Videojuegos para la inclusión educativa. Digital Education Review, 27, 122-137. 
Santos, M. A., Cernadas, F. X. y Lorenzo, M. M. (2014). La inclusión educativa de la inmigración y la formación intercultural del profesorado. Revista Electrónic Interuniversitaria de Formación del Profesorado, 17(2), 123-137. http://doi.org/10.6018/ reifop.17.2.196931.

Sauquillo, P., Ros, C. y Bellver, M. C. (2008). El rol de género en los videojuegos. Teoría de la Educación. Educación y Cultura en la Sociedad de la Información, 9(3), 130-149.

Schouten, B. A., Tieben, R., Van De Ven, A. y Schouten, D. W. (2011). Human behavior analysis in ambient gaming and playful interaction. En Computer Analysis of Human Behavior (pp. 387-403). Londres: Springer. http://doi.org/10.1007/978-0-85729-9949_14.

Serna-Rodrigo, R. y Rovira-Collado, J. (2016). Aportaciones de los videojuegos a la Educación Literaria.

Solé, I. (1992). Estrategias de lectura. Barcelona: Graó.

Toledo, P. y Sánchez-García, J. M. (2017). Realidad Aumentada en Educación Primaria: efectos sobre el aprendizaje. Revista Latinoamericana de Tecnología Educativa-RELATEC, 16(1), 79-92.

Ureña, J. M. M. (2015). Intermedialidad narrativa, modelos estructurales de videojuegos en cine: El caso de Al Filo del Mañana (2014) de Doug Liman. Espéculo: Revista de Estudios Literarios, 54, 93-110. 